\title{
La web corporativa como herramienta estratégica para la construcción de la identidad municipal: análisis de los municipios rurales de España
}

\section{The corporate website as a strategic tool for the construction of municipal identity: Analysis of Spanish rural municipalities}

\author{
Esmeralda López-Alonso; Begoña Moreno-López
}

Cómo citar este artículo:

López-Alonso, Esmeralda; Moreno-López, Begoña (2019). "La web corporativa como herramienta estratégica para la construcción de la identidad municipal: análisis de los municipios rurales en España”. El profesional de la información, v. 28, n. 5, e280525.

https://doi.org/10.3145/epi.2019.sep.25

Artículo recibido el 12-04-2019

Aceptación definitiva: 09-08-2019

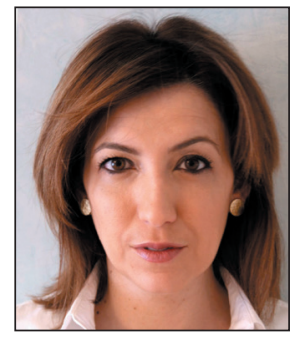

Esmeralda López-Alonso $ه$ https://orcid.org/0000-0003-4263-4581

Universidad Europea de Madrid

Tajo, s/n. 28670 Villaviciosa de Odón

(Madrid), España

esmeralda.lopez@universidadeuropea.es

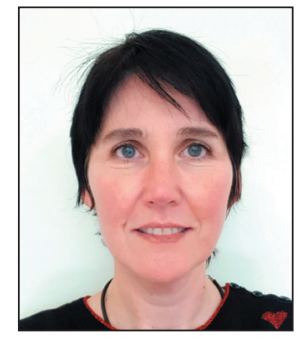

Begoña Moreno-López

https://orcid.org/0000-0002-9035-7286

Universidad Europea de Madrid

Tajo, s/n. 28670 Villaviciosa de Odón

(Madrid), España

begona.moreno@universidadeuropea.es

\section{Resumen}

En la era de la globalización, los municipios rurales en España deben diferenciarse y competir para lograr la fidelización de sus stakeholders (vecinos, turistas, inversores, medios de comunicación, entre otros) y luchar contra la despoblación. La web corporativa es uno de los canales más utilizados por estos públicos para profundizar en el conocimiento de las poblaciones. En este contexto, el presente estudio de carácter exploratorio, tiene como fin evaluar en qué medida algunos municipios rurales utilizan la web institucional como una herramienta estratégica para dar a conocer su identidad. Dados los objetivos, el diseño metodológico está basado en un enfoque cualitativo, con diferentes técnicas de investigación. Los resultados ponen de manifiesto que las webs con estructuras replicadas tienen deficiencias significativas en la gestión de la identidad, tanto desde el punto de vista de la identidad visual corporativa, como de la comunicación con sus públicos y la cultura corporativa.

\section{Palabras clave}

Sitios web; Webs; Sitios web institucionales; Ayuntamientos; Comunicación corporativa; Comunicación organizacional; Identidad corporativa; Identidad visual; Diseño web; Públicos; Pueblos; Rural.

\footnotetext{
Abstract

In the age of globalization, rural municipalities in Spain must differentiate themselves and compete to achieve the loyalty of their stakeholders (neighbours, tourists, investors, media..., among others) and fight against depopulation. The corporate website is one of the most used channels by these audiences to go in depth in the knowledge of the settlements. Therefore, this study is approached in an exploratory way, in order to evaluate whether these rural municipalities use the institutional web as a strategic tool to make known their identity. Given these objectives, the methodological design is based on a qualitative approach, with different research techniques. The results show that websites with replicated structures have significant deficiencies in identity management, both from the point of view of corporate visual identity, communication with their audiences and corporate culture.
} 


\section{Keywords}

Websites; Institucional websites; Corporate communication; Organizational communication; Corporate identity; City councils; Town councils; Visual identity; Web design; Stakeholders; Villages; Municipalities; Rural.

\section{Introducción}

Internet ha crecido, tanto en número de redes como en aplicaciones, convirtiéndose en un potente canal de comunicación audiovisual y multimedia donde la participación de los ciudadanos es cada vez más activa. Así lo demuestra el estudio anual La sociedad digital en España 2017 (Fundación Telefónica, 2018), que indica que un total de 24 millones de españoles entre 16 y 74 años se conectan a diario. Estamos inmersos en la sociedad del conocimiento, un escenario mediático complejo para las administraciones locales que quieran lucrarse de las nuevas formas comunicativas y gestionar eficazmente su reputación en la era del gobierno abierto. En este cambio de paradigma ya no es suficiente ganar las elecciones: los ciudadanos exigen transparencia y mayor participación y es responsabilidad de los poderes públicos abrir nuevas vías de comunicación permanentes (Calderón-Avellaneda, 2011).

La publicación de la Ley 11/2007 de acceso electrónico de los ciudadanos a los servicios públicos (España, 2007) ha conseguido que las entidades locales se apoyen más en la administración electrónica y los usuarios la perciban como un nuevo medio para relacionarse. En este contexto, el sitio web municipal es un excelente instrumento que no sólo sirve como sistema de gestión y de trámites burocráticos, sino también para comunicarse con los diferentes stakeholders (ciudadanos, vecinos, medios de comunicación, empresas, administraciones, proveedores, líderes de opinión, asociaciones, organizaciones no gubernamentales, turistas..., entre otros muchos) y transmitir la marca del municipio. Además, es un canal controlado (Becerra-Muñoz, 2010) que ayuda a dar una mayor visibilidad y trasladar la identidad (Marín-Dueñas; Lasso-De-la-Vega-González; Mier-Terán-Franco, 2016), sin restricciones de espacio. Por ende, podemos decir que es uno de los canales más idóneos para que los municipios, con independencia de su tamaño, difundan su marca e identidad de forma distintiva y coherente, mejorando así su imagen y reputación.

\section{La web municipal es un excelente instru- mento para comunicarse con los stake- holders y transmitir la identidad del mu- nicipio}

Un buen número de autores ha escrito sobre los beneficios que conlleva una gestión de la marca ciudad o marca de destino, destacando que una buena reputación tiene un impacto directo en su desarrollo económico, social, político y cultural. Atrae a más turistas, inversores, eventos, talento (Fernández-Cavia; Huertas-Roig, 2014), fomenta el patriotismo cívico de los ciudadanos y difunde las bondades entre los potenciales residentes (Fernández; Paz, 2005). Por los estudios consultados, la mayoría de las grandes capitales españolas, conscientes de estas ventajas, gestionan su marca corporativa, pero no existen evidencias sobre lo que está ocurriendo en los municipios de menor tamaño que, en muchos casos, sufren grandes problemas de despoblación por el éxodo rural y la regresión demográfica. Este tema es de vital importancia en el informe de la Federación Española de Municipios y Provincias (FEMP, 2017), destacando entre sus bloques temáticos más relevantes el de "Cultura-identidad-comunicación" donde apuesta por mejorar la comunicación de la realidad territorial y potenciarla con nuevas estrategias.

La web corporativa es uno de los instrumentos más utilizados por los públicos para profundizar en el conocimiento de las poblaciones. La mayoría de los ayuntamientos españoles son conscientes de la relevancia de estar presentes en internet, pero sólo la mera existencia de una web corporativa no es suficiente. También es necesario que haya un plan estratégico de comunicación en ese canal y profesionales cualificados que lo gestionen y sepan aprovechar todas las aplicaciones 2.0 para favorecer la interacción y colaboración con todos los públicos de interés. Las administraciones locales en España son muy diversas y no todas cuentan con los recursos ni medios necesarios, acentuándose este problema en los ayuntamientos de menor tamaño (Fundación Telefónica, 2008).

La presente investigación viene determinada porque, a pesar de que existen estudios sobre la marca ciudad en las principales capitales españolas (Puig-Picart, 2009; Saéz-Vegas; Mediano-Serrano; De-Elizagarate-Gutiérrez, 2011; Sixto-García, 2011; Ramos-Ostio, 2012; Cruz-Ruiz; Ruiz-Romero-De-la-Cruz; Zamarreño-Aramendia, 2015), no se han encontrado estudios que hayan profundizado en la web municipal como un canal estratégico para transmitir la identidad corporativa, especialmente en municipios de menos de 10.000 habitantes. De esta realidad se deduce la hipótesis principal de la investigación, que sostiene que los municipios utilizan las webs corporativas para transmitir la identidad municipal y así, obtener una maLa mayoría de los ayuntamientos españoles son conscientes de la relevancia de estar presentes en internet, pero sólo la mera existencia de una web corporativa no es suficiente yor diferenciación. 


\section{Estado de la cuestión}

En los últimos años, en la comunidad académica de nuestro país han proliferado estudios sobre las webs corporativas en los ayuntamientos. De los primeros análisis destacan el de Esteves (2005) enfocado a la gestión pública (información, participación y trámites burocráticos) y el de Rodríguez, Marauri-Castillo y Pérez (2006) que abarca la oferta informativa, la facilidad de uso y la capacidad de respuesta al ciudadano, en las capitales de provincia. El mayor auge se ha dado con la entrada en vigor de la Ley 19/2013 de Transparencia, que obligaba a las administraciones central, autonómica y local a publicar en sus sitios web toda la información relevante para el ciudadano. Destacan proyectos desde el punto de vista de la información institucional (Moreno-Sardà; Molina-Rodríguez-Navas; Corcoy-Rius, 2013; Subires-Mancera; Cuarteto-Naranjo, 2014; Vera-Balanza, 2014; Ruano-López et al., 2016) en los que se analizan comunidades autónomas, abarcando los municipios de mayor tamaño. Estos estudios apuntan que todavía queda un largo camino por recorrer para mejorar la información institucional de las webs de las administraciones locales.

Otra línea de trabajo es la transparencia informativa (Moreno-Sardà; Corcoy-Rius; Molina-Rodríguez-Navas, 2014; Carrascosa-Puerta; Trenta, 2015; Cabezuelo-Lorenzo; Rey-García; Tapia-Frade, 2016; Manfredi-Sánchez et al., 2016). Al igual que los anteriores, son análisis específicos de comunidades autónomas y en todos advierten que existen carencias significativas en esta materia. Fernández-Falero et al. (2017) realizaron un estudio sobre la comunicación política de los ayuntamientos, en el que se indica que las webs de los ayuntamientos extremeños con mayor población tienen deficiencias en la comunicación política y no vienen sólo determinadas por los medios disponibles, sino también por la voluntad política.

Respecto a la usabilidad, sobresale el trabajo de Piñeiro-Naval, Igartua y Marañón (2017) que subraya que los municipios de mayor población tienen portales web con una calidad formal superior; especialmente los del cuadrante suroeste español. Por último, aunque no atañe directamente a esta investigación, son destacables los numerosos estudios que se han centrado en administración electrónica de los portales web municipales, uno de los campos más analizados hasta el momento.

Como se ha podido observar, existen diversas investigaciones sobre el uso y la relación de las tecnologías de la información y comunicación (TIC) en la administración local en España, pero no ocurre lo mismo en la comunicación municipal (Campillo-Alhama, 2012) y, concretamente, en el empleo de la web corporativa desde el prisma de la comunicación institucional y la gestión de los intangibles como la identidad, la imagen o la reputación.

\subsection{Identidad municipal y web corporativa como medio clave de diferenciación}

Aunque el uso lingüístico de los términos de identidad, imagen y reputación está diferenciado, esto no sucede en el entorno profesional, siendo las confusiones terminológicas bastante frecuentes. Al comienzo, la identidad estuvo ligada al diseño gráfico y a aspectos más visuales, pero con el paso del tiempo se ha modificado a una concepción mucho más amplia, entendiéndose como la personalidad y la esencia de una organización. En el caso de la identidad de un municipio, se podría resumir como la suma de características tangibles (construcciones, edificios, bienes culturales, etc.) e intangibles (marca, cultura, historia, costumbres, valores, creencias, actitudes, etc.) que lo definen y lo diferencian del resto.

Tras delimitar el concepto de identidad, es importante conocer los elementos que la componen. Aunque existen varias clasificaciones, la bibliografía señala tres dimensiones principalmente:

- identidad visual corporativa: abarca todos los símbolos, logotipos, colores, tipografías que ayudan a crear un conjunto singular identificador;

- comportamiento corporativo: va muy unido a la cultura y se puede resumir como el conjunto de creencias, valores, costumbres y pautas de conducta que tiene una organización;

- comunicación: entendida no sólo a través de los mensajes, sino también en la forma en la que se comporta la organización.

Para un municipio es clave una buena gestión de la identidad siempre que tenga conexión con sus valores, cultura, historia, personalidad, beneficios, atributos de su población y público objetivo. Una buena gestión de la identidad permite defender los intereses de la ciudad en las relaciones políticas, sociales y económicas que puedan darse (Sáez-Vegas; Mediano-Serrano; De-Elizagarate-Gutiérrez, 2011) y conseguir una mayor identificación en sus públicos de interés para posicionarla como un lugar interesante en la mente de los vecinos, futuros residentes, inversores o turistas, entre otros. Por tanto es indispensable que la conjunción de todos los elementos que la forman se comunique a través de los canales disponibles.

En España existe una gran diversidad de municipios y cada ayuntamiento establece un sistema de gestión de la comunicación, bien sea centralizado o descentralizado, ajustándose a los recursos técnicos, humanos y financieros (Campillo-Alhama, 2011). Históricamente estos emisores de información controlaban los mensajes que ofrecían a través de las relaciones públicas y la
Para un municipio es clave una buena gestión de la identidad siempre que tenga conexión con sus valores, cultura, historia, personalidad, atributos de su población y público objetivo 
publicidad. Desde que surgieran la web 2.0 y los medios sociales ya no es posible, dado que los usuarios pueden ser fuente de información y retroalimentación con las ventajas e inconvenientes que ello conlleva (Alejos-Góngora, 2014). No obstante, el uso adecuado de estos canales ayuda a fomentar una imagen de marca positiva (Ramos-Ostio, 2012).

Desde que surgieran los primeros sitios web de instituciones públicas (local, regional, nacional e internacional) a mediados de los años 1990, Criado-Grande (2009) los ha estudiado ampliamente y ha descrito tres fases:

- Portales informativos o webs de sentido único: destacan contenidos pasivos e información genérica con una interacción muy baja con los ciudadanos. Estas webs se suelen identificar por una relativa capacidad de actualización, usabilidad y accesibilidad escasa y una casi nula definición de los servicios telemáticos.

- Portales interactivos o webs de doble sentido: se identifican por una mayor variedad de contenidos que se transforman en interactivos y una capacidad superior de interacción con el ciudadano a través del correo electrónico o formularios de auto-cumplimentación. Todavía no disponen de los elementos tecnológicos y organizativos para una transacción completa.

- Portales web integradores o webs transaccionales: se basan en la capacidad de una interacción completa con el ciudadano al igual que la transacción integral en la prestación de los servicios públicos. También se caracterizan por un diseño estratégico completo, con contenidos actualizados y dotados de personal suficiente.

El mismo autor apunta que esta clasificación se está ampliando por la evolución de las aplicaciones asociadas a la web 2.0 (blogs, wikis, encuestas, foros, etc.) y otras tecnologías (mensajes a móviles, conexión con PDAs, geolocalización y aplicaciones móviles, entre otras) y en otro estudio posterior (Criado-Grande, 2016) vislumbra que la gobernanza inteligente será un nuevo paradigma de gestión pública basada en las redes sociales, haciendo partícipes a los ciudadanos en las decisiones públicas.

Antes de realizar el contenido de una web se debe tener en cuenta una serie de elementos como (Domínguez-Quintas; Álvarez-Rodríguez; Martí-Pellón, 2012):

- contexto

- audiencia

- información de apoyo

- interactividad

- navegabilidad

- uso.

Respecto a las funciones que debe cumplir una web municipal, Costa-Badía y Giraldo-Luque (2013) apuntan las siguientes:

- información básica

- información de actualidad

- atención al ciudadano

- fomento de la participación

- difusión y promoción de servicios

- difusión de proyectos

- city marketing y desarrollo económico

- rendimiento de cuentas y de gestión (transparencia).

Como hemos podido analizar, esto se ha estudiado desde la óptica del diseño, la usabilidad o las funciones básicas, pero no desde la gestión de la identidad como elemento clave de diferenciación.

\section{Metodología}

El presente estudio aborda de manera exploratoria y tiene como objetivo fundamental evaluar en qué medida algunos municipios rurales en España utilizan la web institucional como una herramienta estratégica para dar a conocer su identidad. Como objetivos específicos destacamos:

- Analizar la importancia que las corporaciones locales dan a la gestión de la identidad corporativa municipal y a la web corporativa como instrumento.

- Comprobar el grado de implantación de las webs corporativas en los municipios rurales y su tipología.

- Determinar el grado de adaptación de la identidad corporativa en las webs con estructuras replicadas.

En función de los objetivos, el diseño metodológico está basado en un enfoque cualitativo con diferentes técnicas de investigación. De esta forma se pretende la triangulación de los resultados del trabajo, así como la compensación de las limitaciones de cada técnica.

En primer lugar, se realiza una revisión de los estudios sobre webs corporativas municipales y gestión de los intangibles como la marca y la identidad. Fruto de esta revisión, se comprueba que no existen evidencias de investigaciones anteriores que abarquen la gestión de la identidad corporativa municipal en el entorno web. En aras de lograr datos de una mayor riqueza informativa se acude a fuentes primarias a través de una encuesta cualitativa, la realización de un programa informático creado ad hoc y el análisis de contenido sobre una muestra representativa de webs corporativas. 


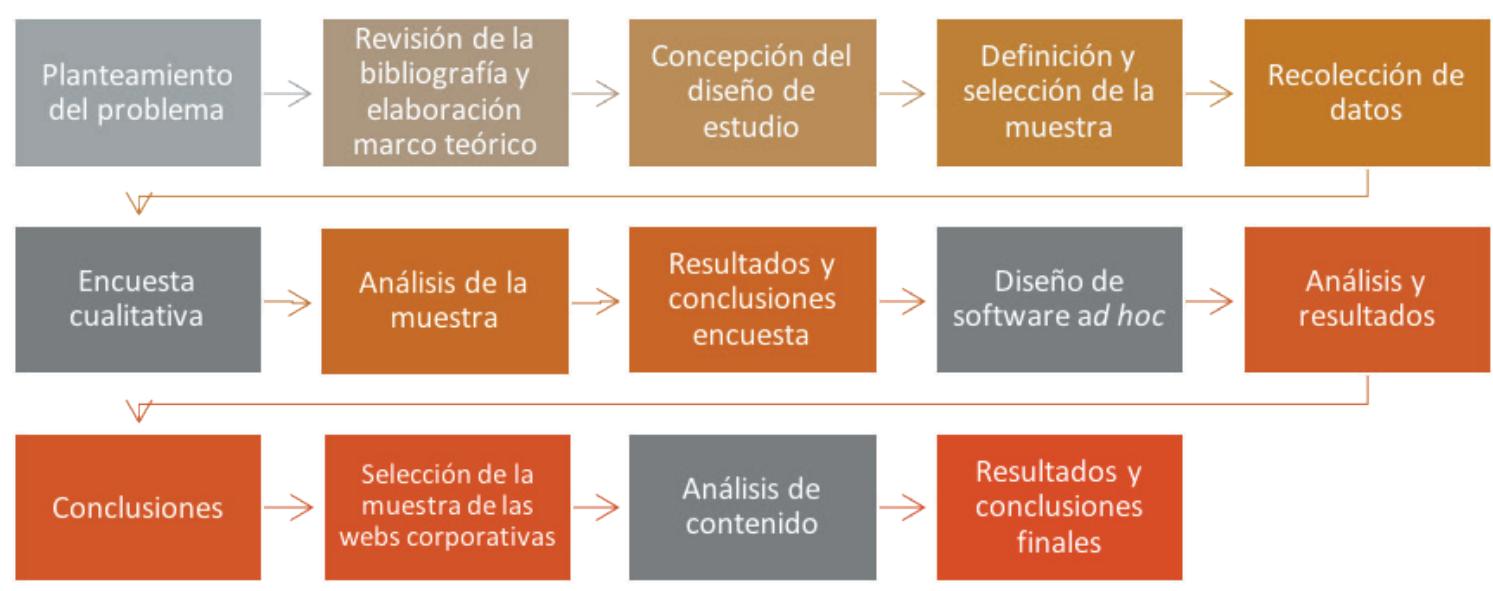

Figura 1. Diseño metodológico

Para determinar el universo de estudio se ha seguido la clasificación más utilizada en la práctica de la estadística oficial, siendo un municipio rural aquel con una población inferior a un determinado umbral. El Instituto Nacional de Estadística (INE) lo considera así cuando cuenta con menos de 10.000 habitantes.

Tabla 1. Clasificación de los municipios por número de habitantes

\begin{tabular}{|l|c|c|}
\hline \multicolumn{1}{|c|}{ Habitantes } & N. de municipios & $\begin{array}{c}\text { Porcentaje que ocupan en el territorio } \\
\text { español }\end{array}$ \\
\hline Menos de 101 & 1.356 & 32,49 \\
\hline De 101 a 500 & 2.642 & 12,34 \\
\hline De 501 a 1.000 & 1.004 & 10,82 \\
\hline De 1.001 a 2.000 & 880 & 11,68 \\
\hline De 2.001 a 5.000 & 950 & 6,71 \\
\hline De 5.001 a 10.000 & 546 & 90,73 \\
\hline Total & 7.378 & \\
\hline
\end{tabular}

Fuente: Elaborado a partir de INE (2019)

Con el fin de conocer la importancia que las corporaciones locales dan a la gestión de la identidad corporativa municipal y a la web corporativa, se hace una prospección inicial mediante un cuestionario auto-administrado en internet. Se realiza la base de datos de los 7.378 ayuntamientos de menos de 10.000 habitantes y se envía el cuestionario a los alcaldes de todos ellos, excepto a 98 de los que no se disponía de su correo electrónico corporativo ni su teléfono. Estos mensajes se distribuyen durante los meses de febrero y mayo de 2018, recibiéndose 968 cuestionarios válidos, lo que supone un nivel de confianza del $99 \%$ y comporta un margen de error del $4 \%$.

De las conclusiones obtenidas en esta primera fase a través del cuestionario y la observación directa se detecta que existen estructuras de webs similares dependiendo de la provincia. Dado el volumen de municipios, para profundizar en este aspecto se ha creado un programa informático que mediante algoritmos analiza las IPs, los CMS y los desarrolladores de los sitios webs, permitiendo concluir que existen dos tipos de webs:

- las que se han creado ad hoc para un único ayuntamiento;

- las que son estructuras replicadas utilizadas por varios municipios (bien porque que han sido cofinanciadas por una administración provincial o regional, o porque el programador es el mismo y replica la estructura).

Una de las tareas más complejas ha sido determinar cuántas plantillas replicables existen en la actualidad. Se observa que en el $80 \%$ de las provincias aparecen estructuras web replicadas en los municipios. Siendo tan mayoritaria esta situación, estudiamos las plantillas replicadas de todas aquellas provincias que tienen más de un $50 \%$ de estructuras similares, con el fin de identificar problemas y posibles áreas de mejora. De cada una de ellas se han seleccionado siete municipios tratando de abarcar todos los tamaños poblacionales de menos de 10.000 habitantes. A pesar de que existen estudios (Pedraza-Jiménez; Codina; Guallar, 2016; Jiménez-Iglesias; Pérez-Montoro; Sánchez-Gómez, 2017) sobre indicadores heurísticos para contenidos y requerimientos para el desarrollo y rediseño de sitios web, el problema que se nos plantea al intentar evaluar el grado de cumplimiento es que no existe ninguna medida de uso generalizado que nos permita cuantificar la identidad corporativa objetivamente. 
Para este fin, se ha diseñado una ficha de categorización en la que se han valorado 24 variables en torno a las tres categorías que representan la gestión de la identidad, cuantificándose mediante una única escala, de 0-2. Debido a la dificultad del análisis de la identidad en las webs corporativas se han seleccionado las variables más relevantes, dejando el resto para un estudio posterior. Para su evaluación se ha usado el análisis de contenido mediante observación visual con una profundidad desde la home (o página inicial) hasta el 4o nivel. Esta segunda fase de análisis se ha llevado a cabo durante los meses de enero a marzo de 2019.

Tabla 2. Indicadores para el análisis de la identidad corporativa en las webs municipales

\begin{tabular}{|c|c|c|}
\hline & Indicador & Escala de evaluación \\
\hline \multicolumn{3}{|c|}{ Identidad visual corporativa } \\
\hline 1 & ¿Se incluye el logotipo/escudo? & $\begin{array}{l}\text { 0: No } \\
\text { 1: Sí, pero no es el del municipio } \\
\text { 2: Sí }\end{array}$ \\
\hline 2 & ¿Se incluye eslogan? & $\begin{array}{l}\text { 0: No } \\
\text { 1: Sí, pero se comparte con otros municipios } \\
\text { 2: Sí }\end{array}$ \\
\hline 3 & ¿Se usan los colores corporativos? & $\begin{array}{l}\text { 0: No } \\
\text { 1: Sí, pero con limitaciones } \\
2: \text { Sí }\end{array}$ \\
\hline 4 & ¿Se usan las tipografías corporativas? & $\begin{array}{l}\text { 0: No } \\
\text { 1: Sí, pero se comparten con otras webs } \\
\text { 2: Sí }\end{array}$ \\
\hline 5 & ¿Se incluye el manual de identidad visual corporativa? & $\begin{array}{l}\text { 0: No } \\
\text { 1: Sí, pero no está completo } \\
\text { 2: Sí }\end{array}$ \\
\hline 6 & $\begin{array}{l}\text { ¿Se incluye el favicon (imagen que aparece en el navegador al } \\
\text { lado del título de la página)? }\end{array}$ & $\begin{array}{l}\text { 0: No } \\
\text { 1: Sí, pero se comparte con otras webs } \\
\text { 2: Sí }\end{array}$ \\
\hline 7 & ¿En el diseño se utilizan imágenes / fotografías del municipio? & $\begin{array}{l}\text { 0: No } \\
\text { 1: Sí, pero no son suficientes } \\
\text { 2: Sí }\end{array}$ \\
\hline 8 & ¿Tiene el diseño adaptado a ordenadores, teléfonos y tabletas? & $\begin{array}{l}\text { 0: No } \\
\text { 1: Sí, pero con limitaciones } \\
\text { 2: Sí }\end{array}$ \\
\hline 9 & $\begin{array}{l}\text { ¿La apariencia visual está adaptada a los parámetros de diseño } \\
\text { actuales? }\end{array}$ & $\begin{array}{l}\text { 0: No } \\
\text { 1: Sí, pero con limitaciones } \\
\text { 2: Sí }\end{array}$ \\
\hline \multicolumn{3}{|c|}{ Comportamiento corporativo } \\
\hline 10 & ¿Hay un apartado dedicado al municipio? & $\begin{array}{l}\text { 0: No } \\
\text { 1: Sí, pero está incompleto } \\
\text { 2: Sí }\end{array}$ \\
\hline 11 & ¿Hay un apartado de historia? & $\begin{array}{l}\text { 0: No } \\
\text { 1: Sí, pero está incompleto } \\
\text { 2: Sí }\end{array}$ \\
\hline 12 & ¿Hay un apartado de costumbres o fiestas populares? & $\begin{array}{l}\text { 0: No } \\
\text { 1: Sí, pero está incompleto } \\
\text { 2: Sí }\end{array}$ \\
\hline 13 & ¿Hay un apartado de visión, misión y valores? & $\begin{array}{l}\text { 0: No } \\
\text { 1: Sí, pero está incompleto } \\
\text { 2: Sí }\end{array}$ \\
\hline 14 & ¿Hay una galería fotográfica sobre el municipio & $\begin{array}{l}\text { 0: No } \\
\text { 1: Sí, pero es escasa o no está actualizada } \\
2: \text { Sí }\end{array}$ \\
\hline 15 & ¿Se incluye contenido multimedia sobre el municipio? & $\begin{array}{l}\text { 0: No } \\
\text { 1: Sí, pero es escaso o no está actualizado } \\
\text { 2: Sí }\end{array}$ \\
\hline 16 & ¿Se informa sobre la normativa municipal? & $\begin{array}{l}\text { 0: No } \\
\text { 1: Sí, pero es muy escasa } \\
\text { 2: Sí }\end{array}$ \\
\hline
\end{tabular}




\begin{tabular}{|c|c|c|}
\hline \multicolumn{3}{|c|}{ Comunicación } \\
\hline 17 & ¿La información está actualizada? & $\begin{array}{l}\text { 0: No } \\
\text { 1: Sí, pero hace más de tres meses } \\
\text { 2: Sí }\end{array}$ \\
\hline 18 & ¿Hay enlaces a redes sociales? & $\begin{array}{l}\text { 0: No } \\
\text { 1: Sí, pero no enlazan a las redes sociales del ayuntamiento } \\
\text { 2: Sí }\end{array}$ \\
\hline 19 & ¿Existen elementos participativos como chats, foros...? & $\begin{array}{l}\text { 0: No } \\
\text { 1: Sí, pero no están actualizados } \\
\text { 2: Sí }\end{array}$ \\
\hline 20 & ¿Hay una sala de prensa? & $\begin{array}{l}\text { 0: No } \\
\text { 1: Sí, pero no está completa } \\
2 \text { :Sí }\end{array}$ \\
\hline 21 & ¿Existe un apartado específico para el ciudadano? & $\begin{array}{l}\text { 0: No } \\
\text { 1: Sí, pero no está actualizado } \\
\text { 2: Sí }\end{array}$ \\
\hline 22 & ¿Existe un apartado específico para proveedores? & $\begin{array}{l}\text { 0: No } \\
\text { 1: Sí, pero no está actualizado } \\
\text { 2: Sí }\end{array}$ \\
\hline 23 & ¿Existe un apartado específico para turistas? & $\begin{array}{l}\text { 0: No } \\
\text { 1: Sí, pero no está actualizado } \\
\text { 2: Sí }\end{array}$ \\
\hline 24 & ¿Existe un apartado para empresas inversoras? & $\begin{array}{l}\text { 0: No } \\
\text { 1: Sí, pero no está actualizado } \\
\text { 2: Sí }\end{array}$ \\
\hline
\end{tabular}

\section{Análisis de datos y discusión de resultados}

\subsection{Percepción de la gestión de la identidad por parte de la corporación local}

De las preguntas formuladas sobre la gestión de la identidad se desprenden datos muy significativos que sirven de base para las fases posteriores de la investigación. La mayoría de las corporaciones locales no han definido la imagen que quieren proyectar de su municipio, sólo un $31 \%$ sí lo ha hecho, y de éstas, un 19,73\% lo ha plasmado en un plan estratégico de comunicación.

Es reseñable igualmente que el $72 \%$ de los municipios no posea todavía un manual de identidad visual corporativa que les permita una diferenciación frente al resto. Hay tres datos relevantes sobre la responsabilidad en la supervisión de la implantación de los ele-

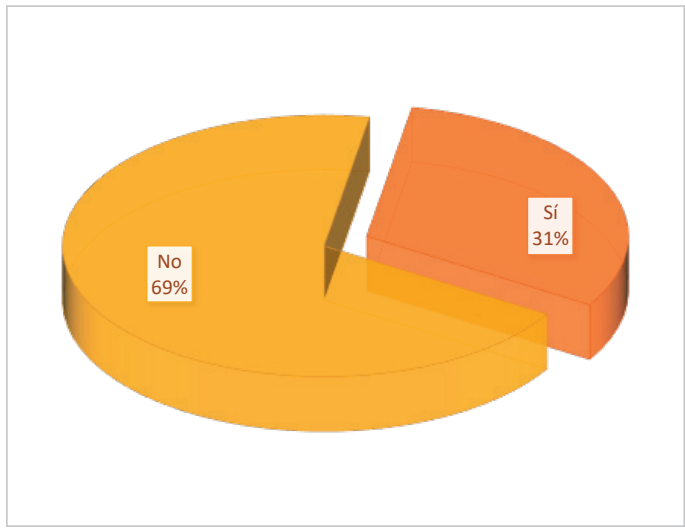

Gráfico 1. Definición de la identidad corporativa mentos corporativos en la comunicación:

- la responsabilidad mayoritariamente recae en un $40,08 \%$ sobre la alcaldía;

- un $24,58 \%$ afirma que nadie ostenta esta responsabilidad;

- sólo en un 8,26\% ésta recae sobre una empresa externa especializada o sobre el departamento de comunicación.

Respecto a la comunicación corporativa, un $74,27 \%$ la considera muy relevante, pero hay una escasa segmentación de los públicos, con una comunicación mayoritaria a los vecinos (98\%), medios de comunicación (51\%) y turistas

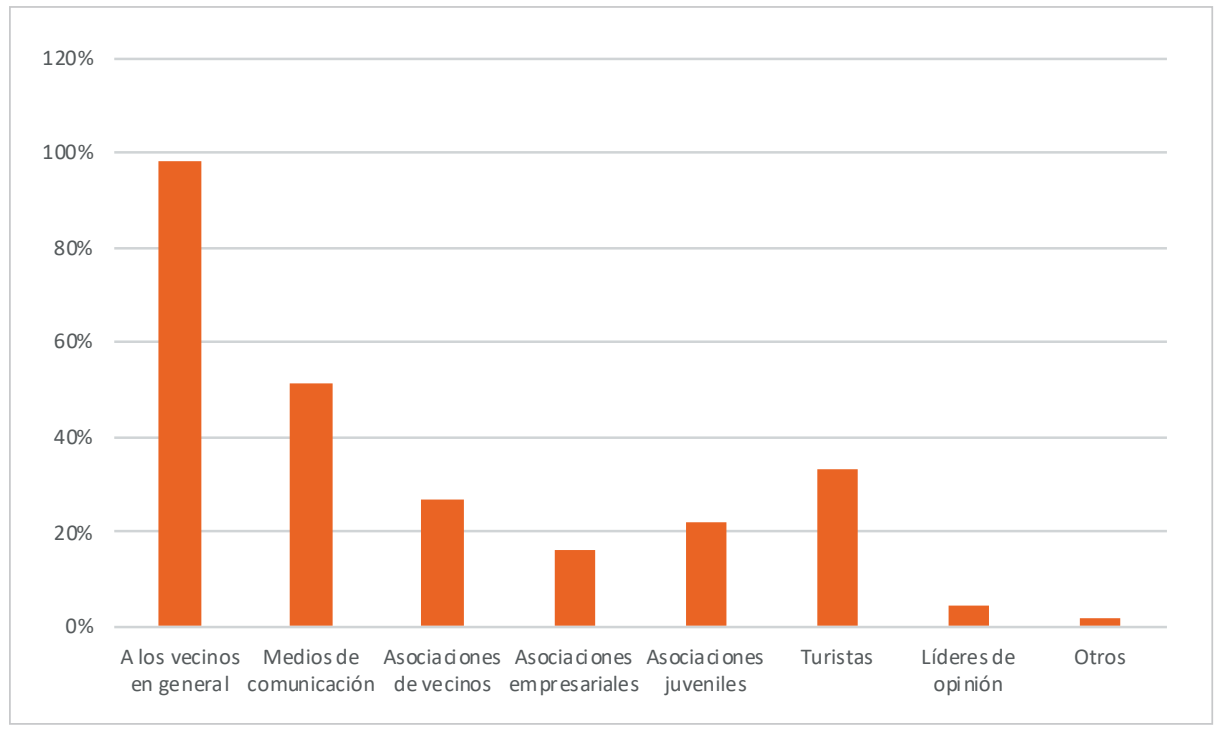

Gráfico 2. Segmentación por públicos 
(33\%) y una adaptación de mensajes muy escasa, lo que supone una disonancia entre lo deseado y lo que realmente se está haciendo en la práctica. Los entrevistados apuntan que esto es fruto de: falta de presupuestos (en un 36,98\%), falta de tiempo $(39,97 \%)$, y escasez de personal cualificado para llevar a cabo esta gestión (29,33\%). Con respecto a este último dato, la responsabilidad de la gestión de la comunicación recae en un $52,58 \%$ sobre la alcaldía y en un $9,5 \%$ sobre ninguna persona. Sólo en un 7,54\% la tiene un departamento de comunicación o una empresa externa especializada.

Las cuestiones referentes a la web corporativa muestran que no todos los municipios poseen web corporativa.

Es interesante destacar los porcentajes de municipios que sí la tienen:

- de menos de 101 habitantes: 25,49\%

- de 101 a 500: 52,94\%

- de 501 a 2.000: 18,62\%

- de 2.001 a 5.000: 2,94\%.

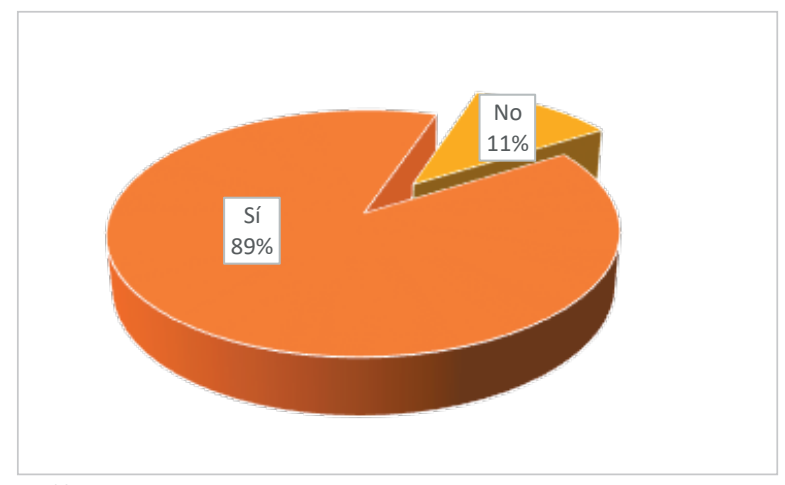

Gráfico 3. Municipios con web corporativa

Sin embargo, todos los municipios de más de 5.000 habitantes la tienen. Es el segundo canal comunicativo más empleado por estos municipios, después del tablón de anuncios (con un $84,29 \%$ ) y por delante de las redes sociales (con un $73,24 \%$ de penetración). Aunque los datos reflejan que la actualización de contenidos es escasa (sólo un 26,73\% posee blogs de actualidad o noticias) y no se emplean adecuadamente medios participativos. Sólo un 34,42\% afirma ofrecer la opción de compartir contenido con otros usuarios, un 6,31\% posee foros participativos con temas que afectan a la comunidad, un $22,14 \%$ de las webs permiten hacer comentarios y sólo en el 1,73\% existe la opción de chat. Con respecto al correo electrónico únicamente un $44,11 \%$ de las webs municipales tienen en la página de inicio el enlace, permitiendo así el contacto directo con el ayuntamiento. En el $55,88 \%$ restante de los casos el email no aparece en ninguna parte de la web, o bien aparece en subsecciones o incrustado como imagen y no como texto.

Finalmente cabe destacar que un $72,66 \%$ tiene acceso La web corporativa, por orden de importancia, es el segundo canal comunicativo utilizado por los ayuntamientos, después del tablón de anuncios

directo a sede electrónica en la página de inicio de la

web corporativa. Asimismo, el análisis pone de manifiesto que no existe una taxonomía unificada para referirse a la misma, y recibe por igual los siguientes nombres: portal del ciudadano, administración electrónica, oficina virtual, e-municipio, registro electrónico, administración-e, servicios telemáticos, carpeta ciudadana, o tele-administración, entre otros.

\subsection{Estructuras replicadas en la web municipal}

Mediante el programa informático detectamos que en un $80 \%$ de las provincias españolas aparecen estructuras web replicadas en los municipios (figura 2). Y que en un $52 \%$ de los casos, hay más de un $50 \%$ de los municipios con estructura replicadas. Esto significa que los sitios web han sido construidos bien con plantillas estandarizadas (Wordpress en un $19,80 \%$, Drupal en un $12,69 \%$ y Joomla en un $8,43 \%$ de los casos) o bien a través de una estructura diseñada ex profeso (en un $56,03 \%$ ), pero que se replica prácticamente igual para varios municipios. Este último caso per-

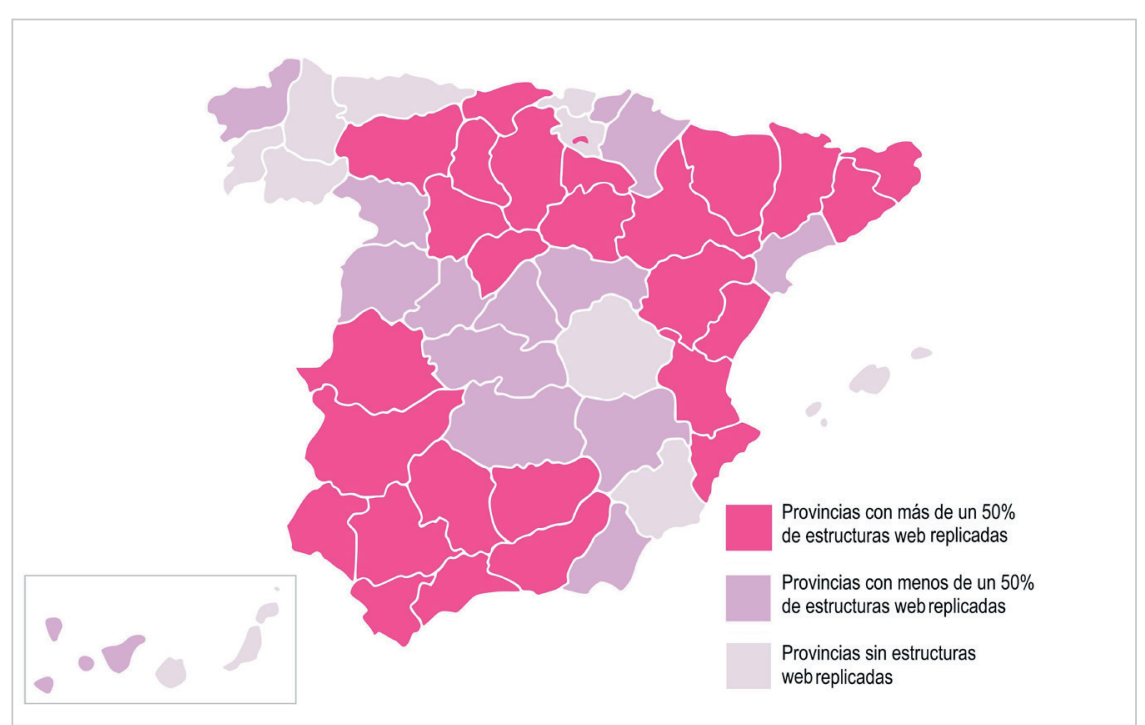

Figura 2. Mapa de provincias según sus estructuras web mitiría una mayor flexibilidad en diseño y contenidos puesto que no obedece a estándares, pero queda estandarizado al repetirse estructura. 


\subsection{Análisis de contenido de las webs replicadas}

En la tabla 3 se presenta una síntesis de los resultados obtenidos por provincias con estructuras web replicadas. Se han analizado 182 municipios y como puede observarse los datos no son muy positivos, sólo 11 provincias superan la puntuación de 1 , no llegando ninguna al 2. Las webs más valoradas son las de los municipios de Asturias, Málaga y Sevilla. Por el contrario, las webs de los municipios de 15 provincias están por debajo del 1, destacando Segovia y Castellón $(0,74)$ y La Rioja $(0,57)$ con la peor puntuación.

Asimismo, las medias sobre las tres categorías principales estudiadas tampoco revelan datos muy positivos. La identidad visual corporativa y la comunicación tienen una puntuación inferior al 1 (0,95 y 0,83 respectivamente). Sólo supera la media la cultura y el comportamiento corporativo con 1,11 .

Tabla 3. Síntesis de los resultados de los municipios, por provincias

\begin{tabular}{|c|c|c|c|c|}
\hline Provincias & $\begin{array}{l}\text { Media identidad visual } \\
\text { corporativa }\end{array}$ & $\begin{array}{c}\text { Media cultura } \\
\text { y comportamiento }\end{array}$ & $\begin{array}{c}\text { Media } \\
\text { comunicación }\end{array}$ & $\begin{array}{l}\text { Media total } \\
\text { provincias }\end{array}$ \\
\hline La Rioja & 0,50 & 0,91 & 0,31 & 0,57 \\
\hline Segovia & 0,78 & 0,71 & 0,73 & 0,74 \\
\hline Castellón & 0,96 & 0,58 & 0,67 & 0,74 \\
\hline Badajoz & 0,66 & 0,97 & 0,63 & 0,75 \\
\hline Cádiz & 1,00 & 0,65 & 0,72 & 0,79 \\
\hline Huesca & 0,93 & 0,90 & 0,55 & 0,79 \\
\hline Lleida & 0,90 & 0,97 & 0,71 & 0,86 \\
\hline León & 0,96 & 0,97 & 0,67 & 0,87 \\
\hline Soria & 0,77 & 1,05 & 0,83 & 0,88 \\
\hline Granada & 0,72 & 1,37 & 0,60 & 0,90 \\
\hline Cáceres & 1,00 & 1,12 & 0,61 & 0,91 \\
\hline Jaén & 0,81 & 1,20 & 0,81 & 0,94 \\
\hline Valladolid & 0,95 & 1,32 & 0,68 & 0,98 \\
\hline Palencia & 0,82 & 1,20 & 0,92 & 0,98 \\
\hline Teruel & 0,97 & 1,12 & 0,87 & 0,99 \\
\hline Alicante & 1,08 & 0,95 & 1,07 & 1,03 \\
\hline Burgos & 0,78 & 1,42 & 0,95 & 1,05 \\
\hline Valencia & 0,90 & 1,32 & 1,01 & 1,08 \\
\hline Barcelona & 0,97 & 1,14 & 1,16 & 1,09 \\
\hline Huelva & 1,20 & 1,11 & 0,98 & 1,10 \\
\hline Córdoba & 1,41 & 0,97 & 1,01 & 1,13 \\
\hline Girona & 1,11 & 1,00 & 1,28 & 1,13 \\
\hline Vizcaya & 1,11 & 1,41 & 0,93 & 1,15 \\
\hline Málaga & 1,20 & 1,30 & 1,16 & 1,22 \\
\hline Sevilla & 1,16 & 1,48 & 1,02 & 1,22 \\
\hline Asturias & 1,19 & 1,70 & 0,95 & 1,28 \\
\hline Media total provincias & 0,95 & 1,11 & 0,83 & 0,96 \\
\hline
\end{tabular}

Se ha podido también comprobar que en las webs hay apartados que están vacíos de contenidos, errores ortográficos, enlaces que no redireccionan correctamente o sedes electrónicas fuera de servicio o como sitios no seguros, situaciones que no ayudan a la gestión de la identidad.

\subsubsection{Resultados sobre la identidad visual corporativa}

Pese a la importancia que tiene la identidad visual corporativa en las webs como principal forma de diferenciación, los resultados muestran que no se está trabajando lo suficiente en esta categoría.

Los elementos básicos de identidad corporativa: logotipo, colores, tipografías y eslogan no están ejecutados pertinentemente. En lo que respecta a los colores y tipografías corporativas, cada estructura replicada utiliza los mismos. En algunos casos, suelen tener tres colores de referencia que van cambiando en función del municipio, pero sin ningún tipo de criterio aparente. Aunque la mayoría de los municipios utilizan el escudo municipal en las webs como logotipo, escasos municipios cuentan con un eslogan que les diferencie del resto. Por lo que la diferenciación se establece en base al escudo y a las imágenes. Como era previsible son muy pocas las que muestran su manual de identidad visual corporativa. 
En cuanto al diseño, algunas webs de los municipios de provincias como León, Lleida, Badajoz o Granada recurren a referencias visuales poco actuales ofreciendo una imagen muy descuidada. Prácticamente la totalidad de estructuras replicadas no disponen de grafismos, ilustraciones o iconos personalizados que ayuden a los usuarios a sintetizar mejor la información mostrada. Las imágenes que se utilizan tampoco ayudan a la diferenciación entre municipios, ya que en varias webs se utilizan las mismas fotografías en la página inicial.

Dentro de la identidad visual corporativa, las variables que repercuten en la reputación de la identidad municipal corresponden al uso del favicon, al título en el navegador y a la adaptabilidad responsive. Esta última es una de las variables con mayor puntuación en esta categoría; bastantes usan su escudo como favicon y el título del navegador aparece correctamente. Aunque se constata también el uso del escudo de España como favicon en varios municipios o el de la diputación correspondiente.

\subsubsection{Resultados sobre la cultura y comportamiento corporativo}

En esta categoría la mayoría de las variables supera la media (1), excepto la exposición de la misión, visión y valores que representan a los municipios, siendo muy pocos los que tratan esta información, así como el uso de archivos multimedia.

Las variables mejor valoradas son historia, costumbres e información municipal. Casi todas las estructuras cuentan con estos apartados donde los datos están lo suficientemente desarrollados. No obstante, no todos disponen del mismo grado de madurez informativa y actualización. Igualmente ocurre con la normativa municipal, existiendo municipios con una información muy detallada y otros en los que la normativa es la genérica que dispone la diputación correspondiente.

Respecto a la galería de imágenes, hay algunas que se encuentran vacías de contenido, poco actualizadas y de baja calidad fotográfica, mermando la imagen municipal.

\subsubsection{Resultados sobre la comunicación}

A pesar de que la web corporativa es un canal idóneo para ofrecer información a todos los grupos de interés y poder relacionarse de forma bidireccional con todas las aplicaciones colaborativas, se constata que las webs replicadas no están diseñadas para estos fines. El principal público al que se dirigen es a los vecinos, seguido de los turistas y en menor grado a los proveedores, con el apartado del perfil del contratante que no siempre funciona. Otros públicos como los medios de comunicación e inversores tienen una puntuación inferior a la media.

Del mismo modo, esto se observa en el uso de aplicaciones colaborativas (chats, foros, blogs, etc.) siendo muy pocos los municipios que las usan y las actualizan. También sucede con las redes sociales: no todas las estructuras incluyen enlaces a las redes sociales del ayuntamiento. En varios municipios enlazan a los partidos políticos que gobiernan o a las propias diputaciones.

Una variable de especial transcendencia es la actualización de contenidos: en nueve provincias, las webs de los municipios tienen una puntuación inferior a la media.

\section{Conclusiones}

A partir del corpus teórico y los resultados obtenidos en el trabajo de campo, podemos concluir que la gestión de la identidad corporativa en los municipios rurales en España se encuentra en un estado incipiente por la falta de recursos económicos y profesionales, siendo muy pocos los municipios que disponen de una estrategia definida de la imagen que quieren proyectar y la comunicación. Una mayoría tiene presencia en internet a través de sus webs corporativas gracias a las financiaciones realizadas por distintas administraciones y fondos europeos. No obstante, en pleno siglo XXI todavía hay municipios que no disponen de la misma, especialmente en los de menos de 5.000 habitantes.

Desde los órganos de gobierno se detecta una inquietud notable por emplear la web como vía comunicativa, dado que es el canal más utilizado, después del tablón de anuncios. Sin embargo, el hecho de que el $80 \%$ de las provincias españolas empleen estructuras de programación replicadas en sus webs municipales supone una merma importante en la construcción de una marca municipal diferenciadora. Existen ejemplos en varias provincias donde la mayoría de las webs institucionales comparten idénticos apartados, tipografías y colores corporativos. En muchos casos, las únicas diferencias notables son el escudo municipal y una fotografía representativa situada en la página inicial. Estas estructuras están diseñadas más para cubrir las exigencias legislativas (como el portal de transparencia o la sede electrónica) que para dotar de una identidad propia a cada municipio y una comunicación abierta. Si atendemos a la clasificación de Criado-Grande (2009) prácticamente la totalidad de las webs con estructuras replicadas son portales informativos con poca actualización y una participación ciudadana muy escasa. A pesar de que son los vecinos el público mayoritario al que se dirigen los mensajes (dejando de lado a los medios de comunicación, turistas, proveedores o posibles inversores, entre otros), la comunicación es unidireccional y fundamentalmente informativa. De aquí se colige que el desarrollo de la web municipal en el entorno rural lleva casi diez años de retraso con respecto a los municipios de más de 10.000 habitantes.

La realidad observada permite concluir que esta herramienta está infrautilizada, existiendo varios puntos de posibles mejoras que, si bien no van a convertir a las estructuras replicadas en un adalid de marca diferencial, pueden contribuir al menos a una mayor operatividad. Cabe recomendar a los municipios que en primer lugar realicen un análisis exhaustivo de los elementos que componen su identidad municipal para que los puedan transmitir de forma coherente a través 
de todos los canales comunicativos, especialmente en las webs institucionales. Sería recomendable que se revisen los parámetros de cada plantilla, pues actualmente tienen escasa libertad para una gestión personalizada. De igual modo, deberían estar actualizadas en los cánones de diseño actuales para que no transmitan valores como obsolescencia, descuido o precariedad.

Si atendemos a la identidad visual corporativa, sería recomendable que el 72,11\% de municipios que aún no poseen un manual de identidad visual corporativa lo creasen. Eso permitiría identificar una gama mayor de tipografías y colores identificables con cada municipio que podrían emplearse en la programación web. En la medida de lo posible, sería necesario que cada municipio incluyera un logotipo o el escudo municipal. Y en caso de no poseerlo, al menos que no emplease los del Estado o la diputación correspondiente, pues esto actúa en detrimento de la imagen. Del mismo modo, sería recomendable que fuese acompañado del slogan que posiciona la identidad y de una galería de imágenes visualmente atractivas sobre el patrimonio material e inmaterial de la localidad.

En definitiva, se concluye la inadecuada gestión de la identidad en este medio en la mayoría de las estructuras replicadas y la hipótesis queda refutada, ya que la web no se está utilizando estratégicamente en favor de la identidad municipal sino como un canal exclusivamente informativo, en el que se detectan abundantes carencias en las categorías estudiadas.

Esta investigación plantea nuevas cuestiones que deben ser abordadas desde una perspectiva más amplia que englobe la gestión de la comunicación a nivel municipal. Es preciso delimitar quién debe ser responsable de la comunicación mediante la web, qué conocimientos y aptitudes debería poseer y cuál debe ser su vinculación con el órgano de gobierno en activo. Del mismo modo, debería profundizarse en si la web se está enfocando al servicio exclusivamente de la comunicación política y no desde el punto de vista de la identidad del municipio. Finalmente, sería recomendable analizar las webs municipales con estructuras no replicadas de municipios de diferentes tamaños poblacionales con el fin de realizar una comparativa y elaborar unas recomendaciones generales sobre la identidad municipal.

\section{Referencias}

Alejos-Góngora, Claudia-Lucía (2014). Responsabilidad social corporativa: De la información a la comunicación. Cuadernos de la Cátedra "La Caixa" de responsabilidad social de la empresa y gobierno corporativo. Barcelona: IESE. https://media.iese.edu/research/pdfs/ST-0367.pdf

Becerra-Muñoz, Elena (2010). "El escaparate online de la empresa. Un nuevo espacio para la comunicación corporativa”. Icono 14, v. 8, n. 1, pp. 207-219.

https://doi.org/10.7195/ri14.v8i1.290

Cabezuelo-Lorenzo, Francisco; Rey-García, Pablo; Tapia-Frade, Alejandro (2016). “Análisis de las herramientas de control ciudadano sobre los representantes públicos: la transparencia informativa municipal en Castilla y León". Revista latina de comunicación social, n. 71, pp. 1261-1279.

https://doi.org/10.4185/RLCS-2016-1145

Calderón-Avellaneda, César (2011). “¿Qué es el gobierno abierto?”. Comunicación política 2.0. Cuadernos Evoca de Comunicación, v. 4. Evoca Comunicación e Imagen, pp. 5-10.

http://www.evocaimagen.com/cuadernos/cuadernos4.pdf

Campillo-Alhama, Concepción (2011). “La dirección de comunicación municipal: estructuras, procesos y entidades declarantes". Revista internacional de relaciones públicas, v. 2, n. 1, pp. 41-60.

https://doi.org/10.5783/RIRP-2-2011-03-41-60

Campillo-Alhama, Concepción (2012). “Investigación en comunicación municipal: estudios y aportaciones académicas”. Vivat academia, n. $117 \mathrm{E}$, pp. 301-323.

https://doi.org/10.15178/va.2011.117E.1035-1048

Carrascosa-Puertas, Lara; Trenta, Milena (2015). “Las webs de los ayuntamientos de Canarias de municipios de más de 50.000 habitantes". En: Molina-Rodríguez-Navas, Pedro. Transparencia de la comunicación pública local. El mapa Infoparticipa (www.mapainfoparticipa.com). La Laguna: Sociedad Latina de Comunicación Social, pp. 133-148. ISBN 97884 15968951

https://doi.org/10.4185/cac78

Costa-Badía, Pere-Oriol; Giraldo-Luque, Santiago (2013). "La alfabetización mediática: una responsabilidad de las administraciones en la época del gobierno electrónico". En: Gutiérrez-García, Elena; La-Porte-Fernández-Alfaro, María-Teresa. Tendencias emergentes en la comunicación de instituciones, pp. 70-82. Barcelona: Editorial UOC. ISBN: 9788490297513

Criado-Grande, Juan-Ignacio (2009). "Tema 7. Comunicación en las administraciones públicas y aproximación a los ciudadanos". Documentación sobre gerencia pública, del Subgrupo A1, Cuerpo Superior, especialidad de Administración General, de la Administración de la Junta de Comunidades de Castilla-La Mancha. ISBN: 9788477885504

http://pagina.jccm.es/ear/descarga/A1T7.pdf 
Criado-Grande, Juan-Ignacio (2016). “Las administraciones públicas en la era del gobierno abierto. Gobernanza inteligente para un cambio de paradigma en la gestión pública". Revista de estudios políticos, n. 173, pp. 245-275. https://doi.org/10.18042/cepc/rep.173.07

Cruz-Ruiz, Elena-de-los-Reyes; Ruiz-Romero-De-la-Cruz, Elena; Zamareño-Aramendia, Gorka (2017). "Marca territorio y marca ciudad, utilidad en el ámbito turístico. El caso de Málaga". International journal of scientific management and tourism, v. 3, n. 2, pp. 155-174.

http://hdl.handle.net/10630/13218

Domínguez-Quintas, Susana; Álvarez-Rodríguez, María-Luz; Martí-Pellón, Daniel (2012). “Dirección de comunicación en internet. Estudio y recomendaciones para los espacios de prensa en webs corporativas desde el análisis de portales en internet de grupos empresariales en Galicia". Revista internacional de relaciones públicas, v. 2, n. 3, pp. 45-70. https://doi.org/10.5783/RIRP-3-2012-03-45-70

España (2007). “Ley 11/2007, de 22 de junio, de acceso electrónico a los ciudadanos a los Servicios Públicos". BOE, n. 150, 23 de junio.

https://www.boe.es/buscar/pdf/2007/BOE-A-2007-12352-consolidado.pdf

Esteves, José (2005). “Análisis del desarrollo del gobierno electrónico en España”. IE working papers WPE05-32. http://www.latienda.ie.edu/working_papers_economia/WPE05-32.pdf

FEMP (2017). Documento de acción. Comisión de despoblación. Listado de medidas para luchar contra la despoblación en España. Federación Española de Municipios y Provincias.

http://www.femp.es/sites/default/files/multimedia/documento_de_accion_comision_de_despoblacion_9-05-17.pdf

Fernández-Cavia, José; Huertas-Roig, Assumpció (2014). "La gestión de las marcas de destino y de territorio desde la perspectiva de las relaciones públicas". Comunicació: revista de recerca i anàlisi, v. 31, n. 1, pp. 9-26.

https://doi.org/10.2436/20.3008.01.117

Fernández-Falero, María-Rosario; Trabadela-Robles, Javier; Garcés-Botacio, Indhira; Ruano-López, Soledad (2017). "Comunicación política de los ayuntamientos a través de sus webs. Caso de Extremadura". El profesional de la información, v. 26, n. 3, pp. 404-410.

https://doi.org/10.3145/epi.2017.may.06

Fernández, Gabriel; Paz, Sergio (2005). “Más allá del marketing de ciudades: hacía una política pública de diseño y gestión de los signos de identificación de ciudad". Scripta nova: revista electrónica de geografía y ciencias sociales, v. 9, n. 194.

http://www.ub.edu/geocrit/sn/sn-194-95.htm

Fundación Telefónica (2008). Las TIC en la administración local del futuro. Barcelona: Editorial Ariel. ISBN: 978840808 1241

https://cutt.ly/8esMW1P

Fundación Telefónica (2018). La sociedad digital en España 2017. Barcelona: Editorial Ariel. ISBN: 9788408184133 https://www.fundaciontelefonica.com/arte_cultura/publicaciones-listado/pagina-item-publicaciones/itempubli/625

INE (2019). Número de municipios por provincias, comunidades autónomas e islas.

https://www.ine.es/daco/daco42/codmun/cod_num_muni_provincia_ccaa.htm

Jiménez-Iglesias, Lucía; Pérez-Montoro, Mario; Sánchez-Gómez, Lydia (2017). “Diseño de información digital: Revisión y clasificación de indicadores heurísticos para contenidos web". El profesional de la información, v. 26, n. 6, pp. 10291046.

https://doi.org/10.3145/epi.2017.nov.03

Manfredi-Sánchez, Juan-Luis; López-Cepeda, Ana-María; Álvarez-Peralta, Miguel; Saiz-Echezarreta, Vanesa; Reig-Cruañes, José (2016). "Transparencia y rendición de cuentas de los municipios de Castilla-La Mancha". Barataria. Revista castellano-manchega de ciencias sociales, n. 21, pp. 175-189.

https://doi.org/10.20932/barataria.v0i21.304

Marín-Dueñas, Pedro-Pablo; Lasso-De-la-Vega-González, Carmen; Mier-Terán-Franco, Juan-José (2016). “La eficacia de la web corporativa en las pequeñas y medianas empresas: un análisis de la usabilidad web". Estudios sobre el mensaje periodístico, v. 22, n. 1, pp. 431-444.

https://doi.org/10.5209/rev_ESMP.2016.v22.n1.52604

Moreno-Sardà, Amparo; Corcoy-Rius, Marta; Molina-Rodríguez-Navas, Pedro (2014). “El mapa Infoparticip@ (www. mapainfoparticipa.com): resultados de la evaluación de las webs corporativas de los 230 municipios que tienen más de 20.000 habitantes de las comunidades autónomas de Andalucía, Aragón, Canarias, Cataluña, Galicia y Madrid: análisis comparativo". En: VI Congreso internacional Latina de comunicación. Universidad de La Laguna. ISBN: 9788415698746 http://www.revistalatinacs.org/14SLCS/2014_actas/143_Moreno.pdf 
Moreno-Sardà, Amparo; Molina-Rodríguez-Navas, Pedro; Corcoy-Rius, Marta (2013). "La información de las administraciones públicas locales. Las webs de los ayuntamientos de Cataluña". Revista latina de comunicación social, n. 68, pp. 502-528.

https://doi.org/10.4185/RLCS-2013-987

Pedraza-Jiménez, Rafael; Codina, Lluís; Guallar, Javier (2016). Calidad en sitios web: método de análisis general, e-commerce, imágenes, hemerotecas y turismo. Barcelona: Editorial UOC. ISBN: 9788490644874

Piñeiro-Naval, Valeriano; Igartua, Juan-José; Marañón, Felipe (2017). “El diseño de las sedes web municipales de España. Una propuesta metodológica para su análisis". Revista española de documentación científica, v. 40, n. 1. https://doi.org/10.3989/redc.2017.1.1368

Puig-Picart, Toni (2009). Marca ciudad: como rediseñarla para asegurar un futuro espléndido para todos. Barcelona: Paidós. ISBN: 9788449322099

Ramos-Ostio, María-José (2012). “Relaciones públicas 2.0: El uso de los medios sociales en la estrategia de comunicación online de marcas ciudad españolas". Revista internacional de relaciones públicas, v. 2, n. 3, pp. 71-90.

https://doi.org/10.5783/RIRP-3-2012-04-71-90

Rodríguez, María-del-Mar; Marauri-Castillo, Iñigo; Pérez, Jesús-Ángel (2006). "La comunicación institucional y de servicios. Las páginas web municipales de las capitales de provincia españolas". Anàlisi, n. 33, pp. 63-78.

https://ddd.uab.cat/pub/analisi/02112175n33/02112175n33p63.pdf

Ruano-López, Soledad; Fernández-Falero, María-Rosario; Garcés-Botacio, Indhira; Trabadela-Robles, Javier (2016). Informe sobre la información publicada en las webs corporativas de los municipios de Extremadura, Resultados $2 \stackrel{a}{a}$ oleada. Informes InfoParticipa. Universidad Autónoma de Barcelona; Universidad de Castilla-La Mancha; Universidad de Extremadura.

Sáez-Vegas, Lucía; Mediano-Serrano, Lucía; De-Elizagarate-Gutiérrez, Victoria (2011). “Creación y desarrollo de marca ciudad. Análisis de los registros de marca de las principales ciudades españolas". Revista de dirección y administración de empresas, n. 18, pp. 125-156.

http://hdl.handle.net/10810/9562

Sixto-García, José (2011). “Marketing para ciudades: las ciudades también se venden, las ciudades también son productos". Pensar la publicidad. Revista internacional de investigaciones publicitarias, v. 4, n. 1, pp. 211-226.

https://revistas.ucm.es/index.php/PEPU/article/view/PEPU1010120211A

Subires-Mancera, María-Purificación; Cuartero-Naranjo, Antonio (2014). “Mapa infoparticip@. La información institucional en las webs de las corporaciones andaluzas de 10.001 a 50.000 habitantes. Déficits informativos". En: VI Congreso internacional Latina de comunicación. Universidad de La Laguna. ISBN: 9788415698746 http://www.revistalatinacs.org/14SLCS/2014_actas/060_Subires.pdf

Vera-Balanza, María-Teresa (2014). “Infoparticip@ Cádiz. La información institucional de las corporaciones locales gaditanas: buenas prácticas y déficits territoriales". En: VI Congreso internacional Latina de comunicación. Universidad de La Laguna. ISBN: 9788415698746

http://www.revistalatinacs.org/14SLCS/2014_actas/099_Vera.pdf

\section{Anexo. Municipios estudiados}

$$
\begin{array}{ll}
a=\text { Menos de } 101 & d=\text { De } 1.001 \text { a } 2.000 \\
b=\text { De } 101 \text { a } 500 & e=\text { De } 2.001 \text { a } 5.000 \\
c=\text { De } 501 \text { a } 1.000 & f=\text { De } 5.001 \text { a } 10.000
\end{array}
$$

\begin{tabular}{|c|c|c|c|c|c|c|c|}
\hline \multirow{2}{*}{ Provincia } & \multirow{2}{*}{ Municipio } & \multicolumn{6}{|c|}{ N. de habitantes } \\
\hline & & $\mathbf{a}$ & b & c & d & e & f \\
\hline Alicante & Beneixama & & & & $x$ & & \\
\hline Alicante & Facheca & $x$ & & & & & \\
\hline Alicante & La Romana & & & & & $x$ & \\
\hline Alicante & Lorcha & & & $x$ & & & \\
\hline Alicante & Murla & & $x$ & & & & \\
\hline Alicante & Relleu & & & & $x$ & & \\
\hline Alicante & San Miguel de Salinas & & & & & & $x$ \\
\hline Asturias & Belmonte de Miranda & & & & $\mathrm{x}$ & & \\
\hline Asturias & Ibias & & & & $x$ & & \\
\hline Asturias & Piloña & & & & & & $x$ \\
\hline Asturias & Soto del Barco & & & & & $x$ & \\
\hline
\end{tabular}




\begin{tabular}{|c|c|c|c|c|c|c|c|}
\hline Asturias & Villanueva de Oscos & & $x$ & & & & \\
\hline Asturias & Villayón & & & & $x$ & & \\
\hline Asturias & Yernes y Tameza & & $x$ & & & & \\
\hline Badajoz & Alconchel & & & & $x$ & & \\
\hline Badajoz & Baterno & & $x$ & & & & \\
\hline Badajoz & Carmonita & & & $x$ & & & \\
\hline Badajoz & Llerena & & & & & & $x$ \\
\hline Badajoz & Mengabril & & $x$ & & & & \\
\hline Badajoz & Valle de Matamoros & & $x$ & & & & \\
\hline Badajoz & Villanueva del Fresno & & & & & $x$ & \\
\hline Barcelona & Begues & & & & & & $\mathrm{x}$ \\
\hline Barcelona & La Pobla de Lillet & & & & $x$ & & \\
\hline Barcelona & Rajadell & & & $x$ & & & \\
\hline Barcelona & Rupit i Pruit & & $x$ & & & & \\
\hline Barcelona & Santa Susanna & & & & & $x$ & \\
\hline Barcelona & Tavèrnoles & & $x$ & & & & \\
\hline Barcelona & Vilanova del Vallès & & & & & & $x$ \\
\hline Burgos & Estépar & & & $x$ & & & \\
\hline Burgos & Medina de Pomar & & & & & & $\mathrm{x}$ \\
\hline Burgos & Merindad de Valdeporres & & $x$ & & & & \\
\hline Burgos & Oña & & & & $x$ & & \\
\hline Burgos & Presencio & & $x$ & & & & \\
\hline Burgos & Roa & & & & & $x$ & \\
\hline Burgos & Valle de Zamanzas & $x$ & & & & & \\
\hline Cáceres & Aceituna & & & $x$ & & & \\
\hline Cáceres & Barrado & & $x$ & & & & \\
\hline Cáceres & Bohonal de Ibor & & & & & $x$ & \\
\hline Cáceres & Conquista de la Sierra & & $x$ & & & & \\
\hline Cáceres & Higuera & $x$ & & & & & \\
\hline Cáceres & Sierra de Fuentes & & & & & $x$ & \\
\hline Cáceres & Zarza de Granadilla & & & & $x$ & & \\
\hline Cádiz & Benaocaz & & & $x$ & & & \\
\hline Cádiz & El Gastor & & & & $x$ & & \\
\hline Cádiz & Grazalema & & & & & $x$ & \\
\hline Cádiz & Jimena de la Frontera & & & & & & $x$ \\
\hline Cádiz & Olvera & & & & & & $x$ \\
\hline Cádiz & Prado del Rey & & & & & & $x$ \\
\hline Cádiz & Villaluenga del Rosario & & & $x$ & & & \\
\hline Castellón & Betxi & & & & & & $x$ \\
\hline Castellón & Canet lo Roig & & & $x$ & & & \\
\hline Castellón & El Toro & & $x$ & & & & \\
\hline Castellón & Forcall & & & & & $x$ & \\
\hline Castellón & Les Alqueries & & & & & $x$ & \\
\hline Castellón & Lucena del Cid & & & & $\mathrm{x}$ & & \\
\hline Castellón & Matet & $x$ & & & & & \\
\hline Córdoba & Iznájar & & & & & $x$ & \\
\hline Córdoba & La Granjuela & & $x$ & & & & \\
\hline Córdoba & La Victoria & & & & & $x$ & \\
\hline Córdoba & Posadas & & & & & & $x$ \\
\hline Córdoba & Torrecampo & & & & $x$ & & \\
\hline Córdoba & Valsequillo & & $x$ & & & & \\
\hline Córdoba & Villaharta & & & $x$ & & & \\
\hline Girona & Anglès & & & & & & $\mathrm{x}$ \\
\hline Girona & La Jonquera & & & & & $x$ & \\
\hline Girona & La Vall d'en Bas & & & & & $x$ & \\
\hline Girona & Les Llosses & & $x$ & & & & \\
\hline Girona & Llambilles & & & $x$ & & & \\
\hline
\end{tabular}




\begin{tabular}{|c|c|c|c|c|c|c|c|}
\hline Girona & Riudaura & & $x$ & & & & \\
\hline Girona & Viladrau & & & & $\mathrm{x}$ & & \\
\hline Granada & Bácor-Olivar & & $\mathrm{x}$ & & & & \\
\hline Granada & Beas de Granada & & & & $\mathrm{x}$ & & \\
\hline Granada & Benamaurel & & & & & $x$ & \\
\hline Granada & Cortes y Graena & & & $x$ & & & \\
\hline Granada & Padul & & & & & & $x$ \\
\hline Granada & Pedro Martínez & & & & $\mathrm{x}$ & & \\
\hline Granada & Polopos & & & & $\mathrm{x}$ & & \\
\hline Huelva & Alosno & & & & & $\mathrm{x}$ & \\
\hline Huelva & Aracena & & & & & & $\mathrm{x}$ \\
\hline Huelva & Arroyomolinos de León & & & $\mathrm{x}$ & & & \\
\hline Huelva & Los Marines & & $\mathrm{x}$ & & & & \\
\hline Huelva & Sanlúcar de Guadiana & & $x$ & & & & \\
\hline Huelva & Santa Bárbara de Casa & & & & $\mathrm{x}$ & & \\
\hline Huelva & Villalba del Alcor & & & & & $x$ & \\
\hline Huesca & Ballobar & & & $\mathrm{x}$ & & & \\
\hline Huesca & Benabarre & & & & $\mathrm{x}$ & & \\
\hline Huesca & Binefar & & & & & & $x$ \\
\hline Huesca & Colungo & & $x$ & & & & \\
\hline Huesca & El Grado & & $\mathrm{x}$ & & & & \\
\hline Huesca & Graus & & & & & $x$ & \\
\hline Huesca & Lalueza & & & $x$ & & & \\
\hline Jaén & Canena & & & & $x$ & & \\
\hline Jaén & Huesa & & & & & $\mathrm{x}$ & \\
\hline Jaén & Lupión & & & $\mathrm{x}$ & & & \\
\hline Jaén & Peal de Becerro & & & & & & $x$ \\
\hline Jaén & Porcuna & & & & & & $\mathrm{x}$ \\
\hline Jaén & Santa Elena & & & $x$ & & & \\
\hline Jaén & Santo Tomé & & & & & $\mathrm{x}$ & \\
\hline La Rioja & Autol & & & & & $x$ & \\
\hline La Rioja & Briones & & & $\mathrm{x}$ & & & \\
\hline La Rioja & Cañas & $\mathrm{x}$ & & & & & \\
\hline La Rioja & Casalarreina & & & & $\mathrm{x}$ & & \\
\hline La Rioja & Fonzaleche & & $x$ & & & & \\
\hline La Rioja & Nájera & & & & & & $\mathrm{x}$ \\
\hline La Rioja & Soto en Cameros & & $x$ & & & & \\
\hline León & Peranzanes & & $x$ & & & & \\
\hline León & Puebla de Lillo & & & $x$ & & & \\
\hline León & San Justo de la Vega & & & & $\mathrm{x}$ & & \\
\hline León & Santa Elena de Jamuz & & & & $\mathrm{x}$ & & \\
\hline León & Torre del Bierzo & & & & & $\mathrm{x}$ & \\
\hline León & Valverde de la Virgen & & & & & & $\mathrm{x}$ \\
\hline León & Villaselán & & $x$ & & & & \\
\hline Lleida & Castell de Mur & & $\mathrm{x}$ & & & & \\
\hline Lleida & Montellà i Martinet & & & & $\mathrm{x}$ & & \\
\hline Lleida & Ribera d'Urgellet & & & $\mathrm{x}$ & & & \\
\hline Lleida & Rosselló & & & & & $x$ & \\
\hline Lleida & Sarroca de Bellera & & $\mathrm{x}$ & & & & \\
\hline Lleida & Termens & & & & $\mathrm{x}$ & & \\
\hline Lleida & Tremp & & & & & & $x$ \\
\hline Málaga & Algarrobo & & & & & & $x$ \\
\hline Málaga & Benarraba & & $x$ & & & & \\
\hline Málaga & Cartajima & & $x$ & & & & \\
\hline Málaga & Istán & & & & $\mathrm{x}$ & & \\
\hline Málaga & Jubrique & & & $x$ & & & \\
\hline Málaga & Sierra de Yeguas & & & & & $\mathrm{x}$ & \\
\hline
\end{tabular}




\begin{tabular}{|c|c|c|c|c|c|c|c|}
\hline Málaga & Tolox & & & & & $x$ & \\
\hline Palencia & Baltanas & & & & $x$ & & \\
\hline Palencia & Cervatos de la Cueza & & $x$ & & & & \\
\hline Palencia & Dueñas & & & & & $x$ & \\
\hline Palencia & Guardo & & & & & & $x$ \\
\hline Palencia & La Pernia & & $x$ & & & & \\
\hline Palencia & Villanuño de Valdavia & $x$ & & & & & \\
\hline Palencia & Villarramiel & & & $x$ & & & \\
\hline Segovia & Abades & & & $x$ & & & \\
\hline Segovia & Cantalejo & & & & & $x$ & \\
\hline Segovia & Cobos de Fuentidueña & $x$ & & & & & \\
\hline Segovia & El Espinar & & & & & & $x$ \\
\hline Segovia & La Matilla & $x$ & & & & & \\
\hline Segovia & Torquemada & & & & $x$ & & \\
\hline Segovia & Torreiglesias & & $x$ & & & & \\
\hline Sevilla & Coripe & & & $x$ & & & \\
\hline Sevilla & El Madroño & & $x$ & & & & \\
\hline Sevilla & El Saucejo & & & & & $x$ & \\
\hline Sevilla & Las Navas de la Concepción & & & & $x$ & & \\
\hline Sevilla & San Nicolás del Puerto & & & $x$ & & & \\
\hline Sevilla & Villamanrique de la Condesa & & & & & $x$ & \\
\hline Sevilla & Villanueva del Ariscal & & & & & & $\mathrm{x}$ \\
\hline Soria & Almazán & & & & & & $x$ \\
\hline Soria & Arcos de Jalón & & & & $x$ & & \\
\hline Soria & Duruelo de la sierra & & & & $x$ & & \\
\hline Soria & El Royo & & $x$ & & & & \\
\hline Soria & Matalebreras & $x$ & & & & & \\
\hline Soria & San Leonardo & & & & & $x$ & \\
\hline Soria & Tardelcuende & & $x$ & & & & \\
\hline Teruel & Calamocha & & & & & & $x$ \\
\hline Teruel & Cretas & & & $x$ & & & \\
\hline Teruel & Fuentespalda & & $x$ & & & & \\
\hline Teruel & Gargallo & $x$ & & & & & \\
\hline Teruel & Híjar & & & & $x$ & & \\
\hline Teruel & Samper de Calanda & & & $x$ & & & \\
\hline Teruel & Valderrobres & & & & & $x$ & \\
\hline Valencia & Alpuente & & & $x$ & & & \\
\hline Valencia & Enguera & & & & & $x$ & \\
\hline Valencia & Gátova & & $x$ & & & & \\
\hline Valencia & Guadassuar & & & & & & $x$ \\
\hline Valencia & Higueruela & & & & $x$ & & \\
\hline Valencia & La Puebla de San Miguel & $x$ & & & & & \\
\hline Valencia & Sollana & & & & & $x$ & \\
\hline Valladolid & Aldea de San Miguel & & $x$ & & & & \\
\hline Valladolid & Medina de Rioseco & & & & & $x$ & \\
\hline Valladolid & Quintanilla de Arriba & & $x$ & & & & \\
\hline Valladolid & San Martín de Valvení & $x$ & & & & & \\
\hline Valladolid & Serrada & & & & $x$ & & \\
\hline Valladolid & Traspinedo & & & $x$ & & & \\
\hline Valladolid & Tudela de Duero & & & & & & $x$ \\
\hline Vizcaya & Bakio & & & & & $x$ & \\
\hline Vizcaya & Gorliz & & & & & & $\mathrm{x}$ \\
\hline Vizcaya & Ibarrangelu & & & $x$ & & & \\
\hline Vizcaya & Mendexa & & $x$ & & & & \\
\hline Vizcaya & Munitibar & & $x$ & & & & \\
\hline Vizcaya & Urduña - Orduña & & & & & $x$ & \\
\hline Vizcaya & Zaratamo & & & & $x$ & & \\
\hline
\end{tabular}




\section{$\mathrm{Mi}$}

\section{La revista del mundo bibliotecario}

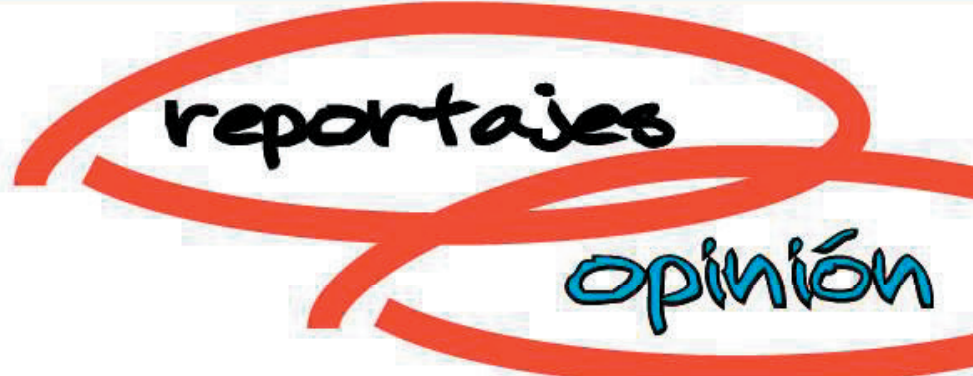

\section{biblliduses}

\section{actualidad}

\section{publicas}

\section{universitarias}

Suscríbete

952235405

www.alonsoquijano.org

belen@alonsoquijano.org 